\title{
Habitat as a surrogate measure of reef fish diversity in the zoning of the Lord Howe Island Marine Park, Australia
}

\author{
Malcolm J. Lindsay ${ }^{1, *}$, Heather M. Patterson ${ }^{1,2}$, Stephen E. Swearer ${ }^{1}$ \\ ${ }^{1}$ Department of Zoology, University of Melbourne, Parkville, Victoria 3010, Australia \\ ${ }^{2}$ Present address: Australian Fisheries Management Authority, Box 7051, Canberra Business Centre, \\ Australian Capital Territory 2610, Australia
}

\begin{abstract}
Marine reserves are being widely implemented as a tool for fisheries management and biodiversity conservation. Although the siting of marine reserves often includes a surrogate measure of diversity, the precision of these measures is rarely tested. To create the marine park at Lord Howe Island, Australia, the New South Wales Marine Parks Authority used habitat as a surrogate for community diversity. The aims of this study were to test the precision of habitat in predicting reef fish assemblage structure, and to investigate changes in precision when varying resolutions of baseline habitat data were available. To achieve this, visual counts of reef fish species and habitat surveys were conducted at 31 sites around the island. Overall, the variations in fish assemblage among sites were moderately correlated with habitat variations, while fish assemblages were weakly spatially autocorrelated, strongly affecting sites within a proximity of $1 \mathrm{~km}$. This spatial autocorrelation demonstrates that both habitat and geographical data combine for greater surrogate precision than habitat alone at this spatial scale. The ability of habitat classes to predict reef fish assemblage structure was dependent on the quality and quantity of baseline data. Differences in assemblage structure were found among habitat classes derived from detailed high-resolution data, but not among habitat classes defined from low-resolution data. This study highlights the need for accurate in situ ecological information to establish precise habitat surrogates and complementary assemblage information to more effectively site marine reserves. Otherwise, reserves may misrepresent fish diversity and be unsuccessful at long-term conservation of marine biodiversity.
\end{abstract}

KEY WORDS: Marine reserves - Marine protected areas · Diversity surrogates · Fish diversity · Spatial autocorrelation · Marine conservation

Resale or republication not permitted without written consent of the publisher

\section{INTRODUCTION}

It is broadly acknowledged that marine biodiversity is under threat, with a great proportion of the world's marine fisheries over-exploited and human activities such as pollution and fishing leading to rapid habitat change and species loss (Hughes et al. 2003). To abate this change, marine reserves are a widely advocated tool for conserving biodiversity and for fisheries management (Lubchenco et al. 2003), and have consequently been established throughout the world with general success. For example, marine reserve estab- lishment has been linked to increased densities, biodiversity, organism size, biomass and reproductive output within protected areas (Halpern 2003).

Despite the ecological importance of marine reserves, reserve boundaries are often chosen based not on ecological grounds, but rather on politics, economics, logistics or public acceptance (Halpern \& Warner 2003). Ecologically driven reserve design requires knowledge of the local biological diversity; however, the resources needed to acquire such information are often limited (Balmford \& Gaston 1999). Given such constraints, one strategy has been to apply 
surrogates that correlate strongly with total species richness and numerical abundance (Olsgard et al. 2003). Surrogates have generally been data sets based on higher taxa (e.g. family-level diversity; Vanderklift et al. 1998), indicator groups (e.g. polychaetes; Olsgard et al. 2003), focal species (e.g. keystone species; Zacharias \& Roff 2001a) or habitat (Ward et al. 1999). However, while these surrogate data are easier and more cost-effective to collect, they may not be very representative of the greater biodiversity at a site (Gladstone 2002).

Habitat is the most frequently chosen surrogate for designing marine reserves. The assumption is that if a certain percentage of all habitat classes present are protected, then the specific biodiversity associated with those habitat classes will also be protected. Despite the widespread use of habitats as surrogates, their efficacy in representing marine biodiversity has seldom been studied. Far more research has been conducted on habitat surrogate use in designing terrestrial reserves (e.g. Sarkar et al. 2005), likely because of the greater logistical difficulties and lack of resources associated with establishing marine parks. However, there are a few examples of studies examining the efficacy of marine habitat surrogates. For example, a study pertaining to the siting of a hypothetical marine reserve network at Jervis Bay, Australia, determined that $>90 \%$ of the diversity of fish, invertebrates and algal taxa would be represented if $>40 \%$ of the habitat classes were protected (Ward et al. 1999). A similar study involving the siting of an actual reserve network in the Seaflower Biosphere Reserve, Colombia, found a close link between both benthic characteristics and fish assemblages to their corresponding surrogate habitat class (Friedlander et al. 2003). Both examples suggest that habitat is an appropriate surrogate of greater diversity. In both cases, however, habitat classes were designated using thorough baseline survey data (Ward \& Jacoby 1992, Diaz et al. 1996), which is not always available.

Habitat class designation within a marine reserve can be based on data of varying quality from a variety of sources. For example, the planning of the Channel Islands Marine Sanctuary in California, USA, incorporated sediment samples, substrate maps, bathymetric maps, aerial photos and habitat survey data in a Geographical Information System (GIS) (Airame et al. 2003). Although the use of remotely sensed data and GIS allows the designation of habitat classes even with a low level of baseline survey data, the efficacy of these habitat maps are rarely ground-truthed (but see Mumby \& Edwards 2002, Purkis 2005). As the surrogate data becomes more remote, there is a possibility that management-defined habitat maps will not represent natural habitat maps and any associated biodiversity.
We explored the influence of baseline data on the fish community at Lord Howe Island (LHI), Australia, where the zone boundaries (e.g. no-take reserve zones) within the newly created biodiversity and fisheries marine reserve were being drafted at the time of this study. Little baseline data existed to aid in reserve design, and thus reserve options were largely based on habitat classes as a diversity surrogate (New South Wales [NSW] Marine Parks Authority 2002). The NSW Marine Parks Authority could draw on only 2 relevant studies completed at LHI. The first collected basic habitat data in conjunction with a detailed coral taxonomic study (Veron \& Done 1979), while the second involved a more in-depth visual survey of the different benthic communities of the island (Harriot et al. 1995). Both studies used some sites around the entire island, but the majority of sites were concentrated along the central region of the west coast. As a result, the habitat classes in this region were designated for the marine park based on detailed information obtained from aerial maps, these 2 studies and extensive local knowledge. In contrast, the habitat classes of the rest of the island were based primarily on coarse visual distinctions from aerial maps and anecdotal information from divers (G. Kelly pers. comm.). Thus, the habitat classification of the central west region was ground-truthed, in contrast to the habitat classification around the rest of the island, resulting in habitat classes of variable accuracy and precision. This difference in data quality and quantity is hereafter referred to as high-resolution and low-resolution habitat classes, respectively.

Given the increase in application of habitat surrogates in developing zoning plans for marine reserves, our aims were to (1) test the precision of habitat data in predicting reef fish assemblage structure and (2) investigate the change in precision of the surrogate when varying resolutions of baseline habitat data are available.

\section{MATERIALS AND METHODS}

Study area. LHI, located $\sim 610 \mathrm{~km}$ off the eastern coast of Australia $\left(31^{\circ} 33^{\prime} \mathrm{S}, 159^{\circ} 04^{\prime} \mathrm{E}\right)$, is the world's most southern coral reef system. It lies near the convergence of the tropical Coral Sea and the temperate Tasman Sea, and is influenced by the eddies and meanders of the southerly flowing East Australian Current. The island is $12 \mathrm{~km}$ long with a large lagoonal reef system along its western side and numerous small islets around its coast (Fig. 1). The fish fauna of LHI comprise subtropical and temperate species thought to have originated through larval dispersal from the Australian mainland coast or the Coral Sea. Roughly $2 \%$ of the 448 marine fish species recorded thus far are endemic 


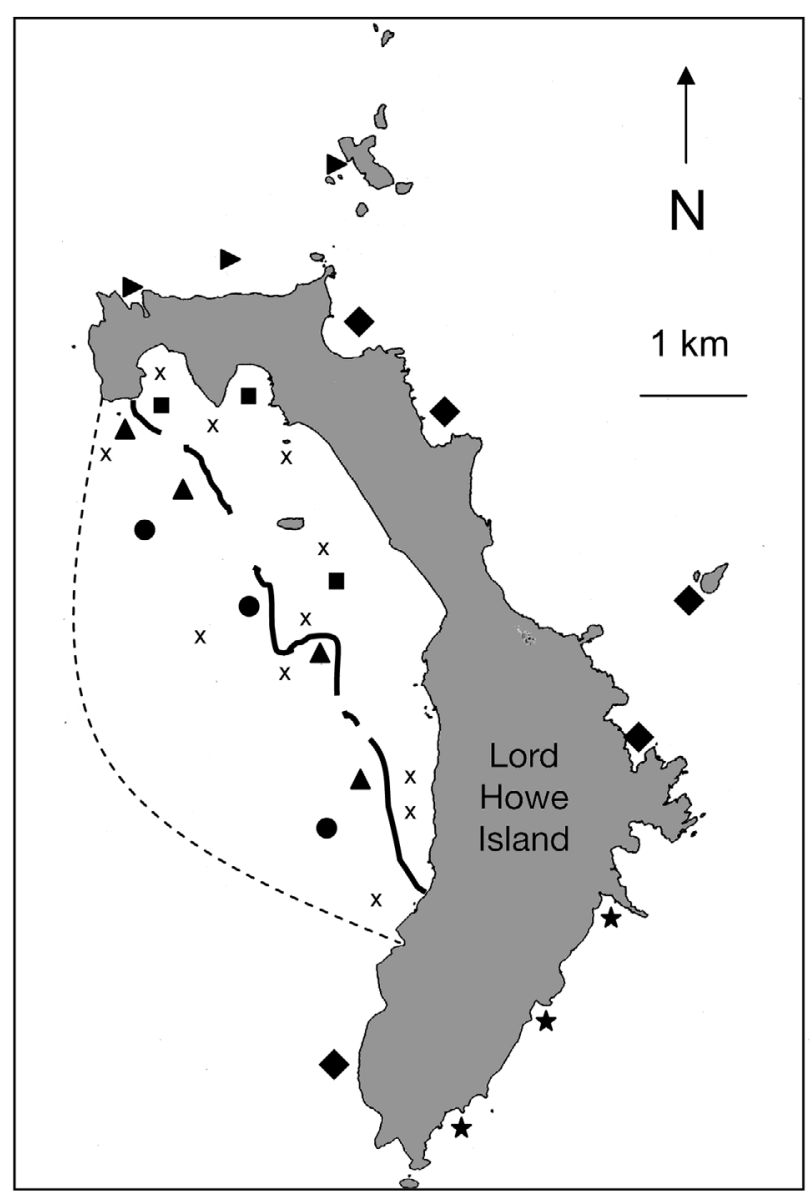

Fig. 1. Sites surveyed for fish and habitat. Sites included in the analysis of the influence of baseline data on the precision of the habitat classes: dense clumping corals (ם), grooved reef fore-slope $(\boldsymbol{\Delta})$, smooth reef fore-slope $(\bullet)$, rheophilic reef $(\boldsymbol{\nabla})$, fringing reef $(\bullet)$ and algae-dominated reef $(\star)$. Sites within the dashed line were in high-resolution habitat classes, while the rest of the sites were in low-resolution habitat areas. Further sites $(x)$ were included in the investigation of the precision of habitat as a predictor of fish assemblage structure. The dark line represents the reef crest of the lagoon

to the island (Francis 1993). In 1999, the waters and underlying seabed out to 3 nautical miles around LHI were proclaimed a state marine park under the NSW Marine Parks Act. Over the subsequent $6 \mathrm{yr}$, the zoning and management plan was drafted and finalised.

Our survey focused on 31 hard substrata sites, between 3 and $15 \mathrm{~m}$ depth, located in the lagoon and on the exposed reefs around the island (Fig. 1). Sites were selected to maximise spatial coverage and were surveyed in random order to avoid possible temporal bias; at times, the weather restricted which sites were accessible. Spatial and habitat-related patterns of the assemblages were examined during 2 field trips: November-December 2003 and JanuaryFebruary 2004.
Sonar transects. Sonar transects were conducted using a XIOS ${ }^{\mathrm{TM}}$ EyeSea sonar navigation system (model: TX Wreck) composed of a sonar transmitter and a receiver. The transmitter was placed at the beginning of each transect and suspended mid-water on a rope between a float and a dive weight. The receiver unit was mounted on a diver's slate and provided information on both the distance and direction from the transmitter. The use of the sonar transects was found to have no significant effect on assemblage structure or abundance when compared to the conventional tape transect and greatly expedited fish surveys (Patterson et al. 2007).

Fish surveys. Visual counts were used to estimate abundance of all conspicuous fish species in 3 replicate $100 \times 10 \mathrm{~m}$ belt transects per site. This belt width increased the probability of encountering mobile and rare species, resulting in greater precision in abundance estimates of these species, while the belt length was small enough to fit within a habitat patch in all but 1 site, where only $50 \mathrm{~m}$ transects were used. Pelagic (e.g. Carangidae) and cryptic (e.g. Muraenidae, Blenniidae or Gobiidae) species were not included in the counts. Five species were deemed very abundant (contributing $>10 \%$ of the overall species abundance: Neoglyphidodon polyacanthus, Stegastes fasciolatus, Chromis hypselepis, Chrysiptera notialis and Pseudolabrus luculentus) and were only surveyed over a $30 \times$ $10 \mathrm{~m}$ belt transect, which provided an ample estimate of their abundance and allowed greater concentration on rarer species. At each site, transects were placed where benthic communities were relatively homogeneous and aligned along a depth contour, reef contour or sand-reef interface. At each site the 3 transects were separated by $50 \mathrm{~m}$. Fish were identified underwater or post hoc using fish identification guides. All fish surveys were carried out by the same diver between 09:00 and 18:00 h.

Habitat. Our measure of habitat was composed of biotic and abiotic variables similar to those used by the NSW Marine Parks Authority when data were available (G. Kelly pers. comm.). Our data were collected at each site using digital photo quadrats taken with a Canon EOS 10 D camera inside a SUBAL underwater housing. In each of these quadrats, a $1 \mathrm{~m}$ PVC rod was used as a size reference. A pilot study using a subset of sites was completed previously to determine the number of quadrats necessary to characterise the habitat along each transect (i.e. provide estimates of percentage cover with $>90 \%$ accuracy) and be feasible in relation to bottom time limits. Based on this analysis, a range of 10 to 30 photo quadrats $\left(1 \mathrm{~m}^{2}\right.$ each) was taken along each transect. Post hoc tests revealed that there was no significant difference between estimates from 10 and 30 random quadrats per transect (non-parametric 
multivariate analysis of variance [NPMANOVA]: $F_{1,38}=$ $0.2644, p=0.9512$ ), and were therefore assumed to give similar estimates of percentage cover.

The photos were analysed using Image Pro 4.5 and Adobe Photoshop Elements 2.0. Photos were calibrated by generating the pixel:cm ratio based on the $1 \mathrm{~m}$ reference rod in each photo. A grid was overlaid and the number of grid squares comprising 1 of 12 different benthic microhabitat classes was tallied, providing a measure of percentage cover. The microhabitat classes (i.e. brain coral, digitate coral, branching coral, plate coral, soft coral, encrusting coral, macroalgae, turf algae, sponge, rubble, sand and seagrass) were chosen to be simple to identify and fish-use related, yet similar to habitat measures used by the NSW Marine Parks Authority to delineate habitat classes (NSW Marine Parks Authority 2002). A square was only counted if $>50 \%$ of the square was filled with a single microhabitat class; on average, 350 squares were counted for each quadrat. In addition, a qualitative measure of complexity, between 1 (low complexity) and 7 (high complexity), was given based on the complexity appearance of each photo quadrat.

Statistical analyses. Habitat surrogate: To investigate how well the habitat surrogate correlated to overall fish assemblage composition, we used a partial Mantel test. This test allows for the exploration of the habitat-fish assemblage correlation while controlling for any spatial autocorrelation in the data. For example, 2 geographically close sites may have more similar fish assemblages due to fish foraging between the sites, not habitat similarities. To achieve this, a fish assemblage dissimilarity matrix was compared to a habitat dissimilarity matrix, after removing the effect of geographical distance (i.e. the partial linear correlation between the assemblage and habitat matrixes after removing the linear effects of the geographical distance matrix). A separate partial Mantel test was then run to investigate the scale of spatial autocorrelation in fish assemblage composition, independent of habitat. The geographical distances between sites were biologically relevant to fishes (i.e. the shortest distance a fish could swim between 2 sites) and all sites were used.

Assemblage composition data were 4 th root-transformed and habitat data were square root-transformed to avoid dominance by abundant species/habitat categories. Matrices were developed using Bray-Curtis dissimilarity coefficients and tests conducted using the zt program. For high precision, 100000 permutations were used and, as the sample size was large, permutations over the null-model residuals were appropriate (Legendre 2000). A simple Mantel test was also used to investigate any spatial autocorrelation of habitat among the sites. This procedure was then repeated for individual species, using untransformed Bray-Curtis dissimilarity coefficients. Due to statistical constraints associated with zero values, only species recorded in $\geq 50 \%$ of the study sites were individually analysed ( $\mathrm{n}=$ 31). For individual species we used the $R$ package for Multivariate and Spatial Analysis v. 4.0 and used 9999 permutations for each analysis.

A correlogram was used to describe the scales at which spatial autocorrelation affects the fish assemblages. The normalised Mantel r statistic was computed for 15 geographical distance classes. The range for each of the first 13 classes was $1 \mathrm{~km}$ (i.e. 13 classes from 1 to $13 \mathrm{~km}$ ), whereas distance class 14 ranged between 13 and $15 \mathrm{~km}$, and distance class 15 ranged between 15 and $22 \mathrm{~km}$. The significance of the Mantel statistic was tested for each distance class, using 1000 permutations with replacement for a 2-tailed test. A global test of significance was then performed using the Bonferroni method, where to be globally significant, $\geq 1$ distance class must be significant at the corrected $\alpha$ level $=0.05 / 15(0.003)$ (Legendre \& Fortin 1989).

Influence of baseline data: Differing resolutions of baseline data could affect the precision of management-defined habitat classes in representing natural habitat classes and their associated biodiversity. Therefore, for our study, the efficacy of a habitat class was defined as how closely related the fish assemblages from sites within the habitat class were compared to those from another habitat class. This efficacy was compared for sites from high- and low-resolution areas to test the influence of their underlying data.

The habitat classes used (Fig. 1) were from the 2 most in-depth NSW Marine Parks Authority habitat maps at the time of the study (NSW Marine Parks Authority 2001, 2003). A subset of sites was used (Fig. 1), ensuring that within each resolution type there were 3 habitat classes, each with 3 or 4 replicate sites. Fish assemblage structure data were 4 th root-transformed prior to analysis. A single-factor analysis of similarities (ANOSIM) was then used to examine the ability of the surrogate to account for changes in fish assemblage structure in all habitat classes combined, the high-resolution habitat classes only and the lowresolution habitat classes only.

Unfortunately, all of the high-resolution sites were restricted to the central west coast of the island, while the low-resolution sites were spread out around the rest of the island (Fig. 1). Thus, the effect of resolution could be confounded by regional differences in the importance of habitat as a predictor of fish assemblage structure. To test this, we performed separate partial Mantel tests as above for each region using our habitat data. If habitat was similarly correlated with fish assemblage structure in both regions, we could be con- 
fident that a significant result from the ANOSIM was due to the resolution of the habitat classes and not spatial confounding of the effect of habitat.

\section{RESULTS}

\section{Habitat as a surrogate}

Overall, the majority of differences in fish assemblage composition (species richness and abundance) of the 159 species observed among sites could be explained by both habitat type and geographical distance. The among-site dissimilarity values based on assemblage composition were significantly correlated with the among-site dissimilarities based on habitat, when correcting for geographical distance $\left(\mathrm{r}_{\text {Mantel }}=\right.$ $0.46, \mathrm{p}=0.001$ [1-tailed]). Thus, there was a relationship of moderate strength between habitat dissimilarities and assemblage dissimilarities and, as the trend was positive, increasing dissimilarity in assemblage composition was associated with increasing dissimilarities in habitat. Although the relationship was weak, the fish assemblage composition dissimilarities were also significantly correlated with the geographical distance among the sites, when the effects of habitat were held constant ( $\mathrm{r}_{\text {Mantel }}=0.17, \mathrm{p}=0.01$ [1-tailed]). As this trend was positive, increasing geographical distance was associated with increasing dissimilarity in fish assemblage composition. The habitat dissimilarities, however, were not autocorrelated with the spatial distances among sites ( $\mathrm{r}_{\text {Mantel }}=-0.02, \mathrm{p}=0.434$ [1-tailed]). Therefore, the overall variation in fish assemblage between sites was strongly related to both habitat differences and geographical distance.

The spatial autocorrelation was highly significant at the smallest distance class (Bonferroni adjusted level: $\alpha=0.05 / 15$ [0.003]; Fig. 2). Therefore, the similarities in fish assemblages between sites within $1 \mathrm{~km}$ were strongly related $\left(\mathrm{r}_{\text {Mantel }}=0.62\right)$ to their geographical proximity. The effects of spatial autocorrelation decreased quickly with increasing distance class, with no other class showing significant spatial autocorrelation. As $\geq 1$ site was significant, the spatial autocorrelation of the fish assemblages was globally significant, echoing the results of the partial Mantel test.

The abundance of individual species was not as tightly correlated with habitat or distance as the overall assemblage data (Table 1). Out of 31 species, 6 $(19 \%)$ were significantly correlated with habitat and 5 $(16 \%)$ with distance. Habitat effects were mainly confined to the family Pomacentridae, whereas both positive and negative spatial autocorrelations were observed in 3 families (Kyphosidae, Pomacentridae and Labridae).

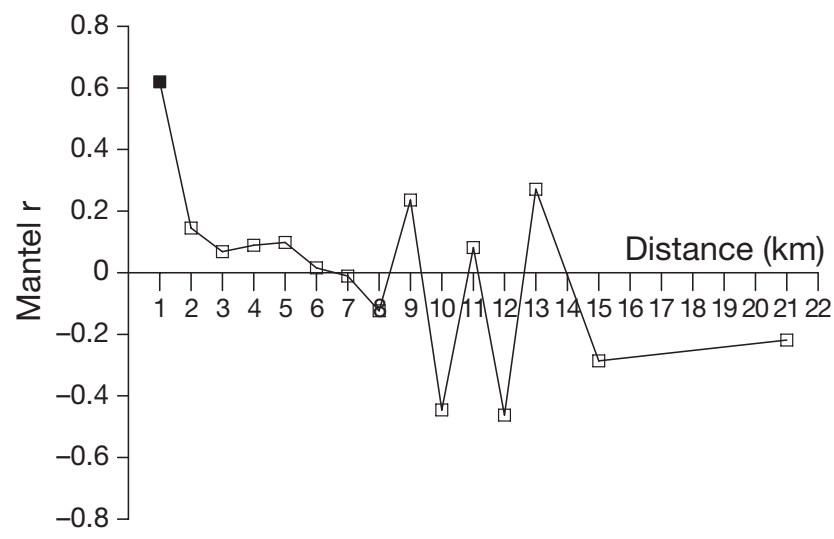

Fig. 2. Spatial autocorrelation in fish assemblages. $\mathbf{0}$ : significant autocorrelation for that distance class $(p=0.001)$

\section{Influence of baseline data}

ANOSIMs indicated that the resolution of the baseline data does affect the efficacy of the habitat classes in predicting fish assemblage structure. When all habitat classes were used, with 10000 randomisations, the results indicated a significant difference in fish assemblage structure among habitat classes (global $\mathrm{R}=$ $0.359, \mathrm{p}=0.001$ ). This difference in assemblage structure among habitat classes was also seen when only the high-resolution habitat classes were used in the analysis (global $\mathrm{R}=0.503, \mathrm{p}=0.01$ ). However, when only the low-resolution habitat classes were used, no significant difference was found, indicating that differences in fish assemblage structure among these habitat classes were similar to differences within a habitat class (global $\mathrm{R}=0.045, \mathrm{p}=0.1$ ). Of the highresolution classes, dense clumping corals was the class most effective in predicting fish assemblage (mean Bray-Curtis dissimilarity $=0.365, \mathrm{SE}=0.033$ ), while the low-resolution habitat class rheophilic reef was the least effective (mean Bray-Curtis dissimilarity $=0.451, \mathrm{SE}=0.039$ ).

Overall, the relationship between fish assemblage, habitat and geographical distance was similar for the 2 regions of baseline data resolution. Therefore the lack of predictive power of the low-resolution habitat classes was not due to a lack of habitat effects on the fish assemblage. Independent of geographical distance, differences in fish assemblages were moderately related to the variation in habitat amongst the high-resolution sites ( $\mathrm{r}=0.40, \mathrm{p}=0.031$ [1-tailed]) and the low-resolution sites $(r=0.51, p=0.029$ [1-tailed]). Independent of habitat, differences in fish assemblages were weakly spatially autocorrelated amongst the high-resolution sites ( $\mathrm{r}=0.23, \mathrm{p}=0.006$ [1-tailed]) and the low-resolution sites $(r=0.16, p=0.05$ [1-tailed]). 
Table 1. Partial Mantel test for the most abundant fish species (found in $>50 \%$ of all the surveyed sites; $\mathrm{n}=$ number of sites). Abundance $\times$ Habitat.Distance: relationship between abundance and habitat while distance is held constant; Abundance $\times$ Distance.Habitat: relationship between abundance and distance while habitat is held constant. Significant results $(p \leq 0.05)$ in bold

\begin{tabular}{|c|c|c|c|c|c|c|}
\hline \multirow[t]{2}{*}{ Family } & \multirow[t]{2}{*}{ Species } & \multirow[t]{2}{*}{$\mathrm{n}$} & \multicolumn{2}{|c|}{$\begin{array}{c}\text { Abundance } \times \\
\text { Habitat.Distance }\end{array}$} & \multicolumn{2}{|c|}{$\begin{array}{c}\text { Abundance } \times \\
\text { Distance.Habitat }\end{array}$} \\
\hline & & & Mantel r & $\mathrm{p}$ & Mantel r & $\mathrm{p}$ \\
\hline Apogonidae & Apogon norfolcensis & 31 & 0.042 & 0.317 & -0.111 & 0.066 \\
\hline Cheilodactylidae & Cheilodactylus ephippium & 24 & 0.114 & 0.152 & 0.013 & 0.402 \\
\hline Mullidae & Parupeneus spilurus & 29 & 0.080 & 0.183 & -0.068 & 0.189 \\
\hline \multirow[t]{2}{*}{ Kyphosidae } & Girella cyanea & 16 & 0.248 & 0.022 & 0.315 & 0.007 \\
\hline & Kyphosus sydneyanus & 18 & 0.046 & 0.287 & -0.096 & 0.114 \\
\hline \multirow[t]{3}{*}{ Chaetodontidae } & Chaetodon flavirostris & 16 & 0.256 & 0.056 & 0.064 & 0.273 \\
\hline & Chaetodon melanotus & 15 & -0.162 & 0.084 & -0.121 & 0.159 \\
\hline & Chaetodon tricinctus & 31 & 0.072 & 0.246 & 0.026 & 0.340 \\
\hline Pomacanthidae & Centropyge tibicin & 16 & 0.064 & 0.275 & 0.098 & 0.190 \\
\hline \multirow[t]{8}{*}{ Pomacentridae } & Amphiprion mccullochi & 15 & 0.056 & 0.317 & 0.173 & 0.116 \\
\hline & Chromis hypsilepis & 24 & 0.401 & 0.002 & -0.051 & 0.324 \\
\hline & Chrysiptera notialis & 24 & 0.031 & 0.345 & -0.058 & 0.262 \\
\hline & Neoglyphidodon polyacanthus & 30 & 0.180 & 0.017 & 0.167 & 0.012 \\
\hline & Parma polylepis & 31 & 0.413 & 0.011 & -0.071 & 0.300 \\
\hline & Plectroglyphidodon dickii & 16 & 0.152 & 0.059 & 0.076 & 0.172 \\
\hline & Stegastes fasciolatus & 24 & 0.194 & 0.031 & -0.018 & 0.472 \\
\hline & Stegastes gasgoynei & 29 & 0.110 & 0.139 & 0.192 & 0.028 \\
\hline \multirow[t]{11}{*}{ Labridae } & Anapses elegans & 31 & -0.033 & 0.418 & 0.049 & 0.262 \\
\hline & Coris bulbifrons & 31 & 0.092 & 0.199 & 0.164 & 0.057 \\
\hline & Coris picta & 18 & -0.047 & 0.329 & 0.098 & 0.124 \\
\hline & Gomphosus varius & 21 & 0.045 & 0.301 & 0.139 & 0.087 \\
\hline & Labroides dimidiatus & 27 & -0.060 & 0.327 & -0.134 & 0.025 \\
\hline & Pseudolabrus luculentus & 31 & 0.090 & 0.162 & -0.027 & 0.413 \\
\hline & Notolabrus incriptus & 19 & -0.148 & 0.161 & -0.107 & 0.113 \\
\hline & Stethojulis bandanensis & 27 & 0.016 & 0.390 & 0.165 & 0.072 \\
\hline & Thalassoma amblycephalum & 16 & -0.035 & 0.348 & -0.108 & 0.037 \\
\hline & Thalassoma lutescens & 28 & -0.108 & 0.173 & 0.163 & 0.056 \\
\hline & Thalassoma purpureum & 27 & -0.036 & 0.415 & -0.021 & 0.473 \\
\hline Scaridae & Scarus ghobban & 18 & 0.343 & 0.009 & -0.008 & 0.562 \\
\hline Blennidae & Plagiotremus tapeinosoma & 25 & 0.083 & 0.213 & -0.118 & 0.088 \\
\hline Acanthuridae & Prionurus maculatus & 20 & -0.041 & 0.370 & 0.010 & 0.382 \\
\hline
\end{tabular}

\section{DISCUSSION}

\section{Habitat as a surrogate}

Our study demonstrated a moderately strong relationship between habitat and fish assemblage structure in the LHI Marine Park, as also seen in other studies at different locations (Williams \& Bax 2001, Curley et al. 2002, Gladstone 2007). Habitat association is often driven by site-specific species, as reef fish often have specialised habitat requirements (e.g. Anderson et al. 1981). Interestingly, our individual species analyses indicated that few abundant species were significantly related to habitat. Our interpretation of this result is that the association between fish assemblage and habitat may be driven partially by variation in the presence/absence of less common species, which we were unable to individually analyse. This may also be a consequence of habitat specialisation, as we would expect habitat specialist species to be less common than habitat generalist species that utilise a wide variety of habitat types. Indeed, studies of coral-dwelling gobies have demonstrated that species inhabiting few coral species are less abundant than those that inhabit a wide variety of coral species (Munday 2000). Consequently, it is the less common species that most benefit from the inclusion of multiple and diverse habitat classes through the use of this surrogate.

Spatial autocorrelation also contributed significantly to the similarity in fish assemblages $<1 \mathrm{~km}$ apart, increasing the explanatory power of the surrogate. This result parallels results from other studies in which fish assemblages only begin to exhibit major differences at 1 to $2 \mathrm{~km}$ separation (Curley et al. 2002). These autocorrelation patterns are most likely attributed to biotic processes, both pre- and post-settlement. Positive spatial autocorrelation has been documented in recruitment patterns at spatial scales relevant to our study (e.g. Hamilton et al. 2006). If recruitment is limiting, this recruitment pattern can result in positive spa- 
tial autocorrelation in adult reef fish abundance (e.g. Doherty \& Fowler 1994). This is most likely to occur with species that are limited in post-settlement movement, such as the territorial damselfishes (family: Pomacentridae), potentially explaining their positive spatial autocorrelation in the present study. Other species exhibit regular small-scale movements over and between reefs to cover larger feeding grounds (e.g. goatfish; Meyer et al. 2000). This movement makes these areas more homogeneous in their assemblage, also resulting in positive spatial autocorrelation. This movement may account for the positive autocorrelation observed by the largely herbivorous Girella cyanea in the present study. Interestingly, negative autocorrelation was exhibited by numerous wrasse species (family: Labridae). This is most likely due to their habit of aggregating in social groups and moving from site to site for mating purposes (Warner 1995). If these aggregations form at spatial scales $<1 \mathrm{~km}$, then nearby sites will experience negative spatial autocorrelation.

Due to the spatial autocorrelation at small scales, fish assemblages differed independently of habitat, thus affecting the accuracy of the surrogate. In using habitat as a surrogate of fish assemblage structure, sites within $1 \mathrm{~km}$ of each other exhibited false heterogeneity, where 2 sites are heterogeneous in habitat but homogeneous in fish assemblage (Stevens \& Connolly 2004). Conversely, any negative spatial autocorrelation would lead to false homogeneity, where 2 sites are homogeneous in habitat but heterogeneous in fish assemblage (Stevens \& Connolly 2004). In order to avoid such inaccuracies, it has been suggested that spatial autocorrelation be included in environmental surrogates of terrestrial reserves (Bonn \& Gaston 2005). Similarly, we recommend that spatial autocorrelation be investigated and controlled for in the use of surrogates in future marine reserves. This information can only be gained from assemblage-level data. The inclusion of spatial autocorrelation would not only increase surrogate accuracy, but would also introduce biotic processes into reserve management, as spatial autocorrelation is most likely a result of biotic processes at this scale. A greater inclusion of biotic processes has been recommended for marine reserve management, but is often too difficult to measure (Zacharias \& Roff 2000). In the absence of more indepth data, spatial autocorrelation could represent a coarse proxy of some biotic processes.

This study raises the question of how much weight to place on biotic assemblage data versus abiotic habitat data in siting marine reserves. The answer depends largely on the spatial scale in question. The results presented here, as in other studies (Ward et al. 1999, Stevens \& Connolly 2004, Gladstone 2007), indicate that at scales of tens of $\mathrm{km}$, surrogate accuracy is greatly increased with the addition of assemblagelevel data. In contrast, at larger scales of hundreds to thousands of $\mathrm{km}$, surrogate accuracy changes little with the addition of assemblage-level data (Long et al. 1997, Williams \& Bax 2001, Zacharias \& Roff 2001b). This pattern is not unexpected, as at the larger scales (hundreds to thousands of $\mathrm{km}$ ), abiotic factors (e.g. temperature) fluctuate more than at local scales, having greater effect on assemblages than biotic factors. In contrast, at smaller scales (below tens of $\mathrm{km}$ ), biotic processes (e.g. species-specific behaviours, species interactions) tend to vary more than at larger scales, having a greater effect on assemblages than abiotic factors. However, exceptions do exist, such as the larger-scale biotic process of migration (Zacharias \& Roff 2000). We therefore recommend that marine reserve managers create surrogates that are scaledependent in their composition, obtaining and including both habitat and assemblage data at smaller scales (below tens of $\mathrm{km}$ ), while relying on habitat data alone at larger scales (hundreds to thousands of $\mathrm{km}$ ). This scale-dependent composition could easily be incorporated into hierarchical reserve network systems being established by many countries (Zacharias \& Roff 2000). Australia's National Representative System of Marine Protected Areas (NRSMPA) has a hierarchy of 5 scaled ecological units: bioregion, ecosystem, habitat, community/population and species/individual (ANZECC TFMPA 1999). Therefore, in Australia, assemblage data should be appropriately included in habitat surrogates being utilised at the species/individual, community/population and habitat scales.

\section{Influence of baseline data}

Our results indicated that the quality of baseline data used to establish habitat classes can affect the efficacy of the surrogate habitat classes to predict fish assemblage structure. We determined that these results were not confounded by the concentration of each habitat class in a specific region on the island, as differences in habitat were similarly related to variation in fish assemblage among the sites in the 2 regions. If our results were confounded, the low-resolution fish assemblages would show more distinction between habitat classes than those from the high-resolution region. This is contrary to our findings. Instead, highresolution classes used to describe sites on the central west coast of the island demonstrated significant differences in fish assemblage structure among habitat classes. In contrast, sites described by low-resolution classes were located around the rest of the island and demonstrated no significant difference in the reef fish 
assemblage among classes. We suspect that the lowresolution habitat classes would be similarly ineffective in describing assemblage differences in other taxonomic groups.

This result was not surprising considering how the 2 types of sites were classified. High-resolution sites were derived using previous studies (i.e. Veron \& Done 1979, Harriot et al. 1995), aerial photos (which were quite detailed for the often shallower sites), and extensive anecdotal evidence and local knowledge as the central west area is used daily and is well known to local residents. The low-resolution classes, however, were located at sites that are less known to local residents, with the exception of a few local divers, and where no detailed habitat studies have been conducted (with the exception of the present study). Given the paucity of information that existed at these sites, it was not unexpected that the subsequent habitat classes were less effective at predicting fish assemblage structure than the high-resolution habitat classes. Consequently, if these low-resolution habitat classes are not adequately representing assemblage structure, then reserve boundaries based on them will not adequately protect fish or possibly higher community-level diversity. Thus, the resolution of data used in a surrogate can seriously jeopardise a reserve's goal of protecting marine biodiversity at this scale. We therefore recommend that habitat surrogates should only be used when thorough in situ baseline data are available to guide habitat map formation.

\section{CONCLUSIONS}

Our purpose here is not to criticise the LHI Marine Park and how the boundaries of that reserve were determined. We acknowledge that we have examined only the fish assemblages, and the LHI Marine Park was designed to encompass all taxonomic groups. We also acknowledge that surrogates are generally used because assemblage-level data are unavailable or too expensive, especially in developing countries. However, there is little value in utilising a surrogate if it is ineffective; a surrogate is only as good as the data on which it is based. In the event of no or little data existing, in situ surveys need to be undertaken. This study required relatively little in the way of time and resources to gather detailed ecological information. These in situ surveys not only improved the precision of the surrogate through the habitat data, but allowed simultaneous collection of assemblage-level data. These assemblage data can further increase surrogate precision by controlling for any assemblage-level spatial autocorrelation, can be used in parallel with the habitat surrogate in siting reserve boundaries at smaller scales (below tens of $\mathrm{km}$ ) and can be used as baseline data to assess the reserve's progress through comparisons with future surveys.

We are not advocating that reserve formation should be stalled or stopped due to a lack of baseline data. However, now that reserve formation is becoming more formalised through national reserve network systems, efficient surrogate use should also become more formalised. If a surrogate is inaccurate in describing greater diversity, then reserve boundaries may misrepresent local biodiversity and the reserve may fail to adequately conserve the local marine biodiversity it was established to protect.

Acknowledgements. We thank the NSW Marine Parks Authority, in particular G. Kelly, for support, knowledge and logistical assistance. Thanks to the staff at Howea Divers for providing invaluable service and friendship on the island. Helpful field assistance was provided by A. Crean and V. Thompson. Thanks to G. Lindsay from O'Brien Maritime Consultancy Pty Ltd and M. Edmunds from Australian Marine Ecology Pty Ltd for their help with statistics and programming. Comments by B. Halpern improved an earlier draft of the manuscript. Funding for this project was provided by an Australian Geographic grant to H.M.P. and an Australian Research Council grant to S.E.S.

\section{LITERATURE CITED}

Airame S, Dugan J, Lafferty KD, Leslie H, McArdle D, Warner RR (2003) Applying ecological criteria to marine reserve design: a case study from the California Channel Islands. Ecol Appl 13:S170-S184

Anderson GRV, Ehrlich AH, Ehrlich PR, Roughgarden JD, Russell BC, Talbot FH (1981) The community structure of coral reef fishes. Am Nat 117:476-495

ANZECC TFMPA (Australian and New Zealand Environment and Conservation Council, Task Force on Marine Protected Areas) (1999) Understanding and applying the principles of comprehensiveness, adequacy and representativeness for the NRSMPA, version 3.1. Marine Group Environment Australia, Canberra

Balmford A, Gaston KJ (1999) Why biodiversity surveys are good value. Nature 398:204-205

Bonn A, Gaston KJ (2005) Capturing biodiversity: selecting priority areas for conservation using different criteria. Biodivers Conserv 14:1083-1100

Curley BG, Kingsford MJ, Gillanders BM (2002) Spatial and habitat-related patterns of temperate reef assemblages: implications for the design of Marine Protected Areas. Mar Freshw Res 53:1197-1210

Diaz JM, Diaz G, Garzon-Ferreira J, Geieter J, Sanchez JA, Zea S (1996) Atlas de los arrecifes coralinos del Caribe colombiano. Serie de publicaciones especiales 2. INVEMAR, Santa Marta, Colombia

Doherty P, Fowler T (1994) An empirical test of recruitment limitation in a coral reef fish. Science 263:935-939

Francis MP (1993) Checklist of the coastal fishes of Lord Howe, Norfolk, and Kermadec Islands, southwest Pacific Ocean. Pac Sci 47:136-170

Friedlander A, Sladek Nowlis J, Sanchez JA, Appeldoorn R, Usseglio P, McCormick C, Bejarano S, Mitchell-Chui A 
(2003) Designing effective marine protected areas in Seaflower biosphere reserve, Columbia, based on biological and sociological information. Conserv Biol 17: 1769-1784

Gladstone W (2002) The potential value of indicator groups in the selection of marine reserves. Biol Conserv 104: 211-220

Gladstone W (2007) Requirement for marine protected areas to conserve the biodiversity of rocky reef fishes. Aquat Conserv Mar Freshw Ecosyst 17:71-87

Halpern BS (2003) The impact of marine reserves: Do reserves work and does size matter? Ecol Appl 13: S117-S137

Halpern BS, Warner RR (2003) Matching marine reserve design to reserve objectives. Proc R Soc Lond B 270: 1871-1878

Hamilton SL, White JW, Caselle JE, Swearer SE, Warner RR (2006) Consistent long-term spatial gradients in replenishment for an island population of coral reef fish. Mar Ecol Prog Ser 306:247-256

Harriot VJ, Harrison PL, Banks SA (1995) The coral communities of Lord Howe Island. Mar Freshw Res 46:457-465

Hughes T, Baird AH, Bellwood DR, Card M and others (2003) Climate change, human impacts, and the resilience of coral reefs. Science 301:929-933

Legendre P (2000) Comparison of permutation methods for the partial correlation and partial Mantel tests. J Stat Comput Sim 67:37-73

Legendre P, Fortin MJ (1989) Spatial pattern and ecological analysis. Vegetatio 80:107-138

Long BG, Bode L, Mason L, Pitcher CR (1997) Seabed current stress predicts the distribution and abundance of epibenthos in Torres Strait. Report to Australian Fisheries Management Authority. Commonwealth Scientific and Industrial Research Organisation, Australia

Lubchenco J, Palumbi SR, Gaines SD, Andelman S (2003) Plugging a hole in the ocean: the emerging science of marine reserves. Ecol Appl 13:S3-S7

Meyer CG, Holland KN, Wetherbee BM, Lowe CG (2000) Movement patterns, habitat utilization, home range size and site fidelity of whitesaddle goatfish, Parupeneus porphyreus, in a marine reserve. Environ Biol Fish 59: 235-242

Mumby PJ, Edwards AJ (2002) Mapping marine environments with IKONOS imagery: enhanced spatial resolution can deliver greater thematic accuracy. Remote Sens Environ 82:248-257

Munday PL (2000) Interactions between habitat use and patterns of abundance in coral-dwelling fishes of the genus Gobiodon. Environ Biol Fish 58:355-369

NSW Marine Parks Authority (2001) Lord Howe Island Marine Park issues paper. NSW Marine Parks Authority, Lord Howe Island

NSW Marine Parks Authority (2002) Draft zoning plans for the

Editorial responsibility: Otto Kinne (Editor-in-Chief), Oldendorf/Luhe, Germany
Lord Howe Island Marine Park. NSW Marine Parks Authority, Lord Howe Island

NSW Marine Parks Authority (2003) Draft zoning plan for Lord Howe Island Marine Park. NSW Marine Parks Authority, Lord Howe Island

Olsgard F, Brattegard T, Holthe T (2003) Polychaetes as surrogates for marine biodiversity: lower taxonomic resolution and indicator groups. Biodivers Conserv 12: 1033-1049

Patterson HM, Lindsay MJ, Swearer SE (2007) Use of sonar transects to improve efficiency and reduce potential bias in visual surveys of reef fishes. Environ Biol Fish 78: 291-297

Purkis SJ (2005) A 'reef-up' approach to classifying coral habitats from IKONOS imagery. IEEE Trans Geosci Remote Sens 43:1375-1390

Sarkar S, Justus J, Fuller T, Kelley C, Garson J, Mayfield M (2005) Effectiveness of environmental surrogates for the selection of conservation area networks. Conserv Biol 19: 815-825

Stevens T, Connolly RM (2004) Testing the utility of abiotic surrogates for marine habitat mapping at scales relevant to management. Biol Conserv 119:351-362

Vanderklift MA, Ward TJ, Phillips JC (1998) Use of assemblages from different taxonomic levels to select areas for conserving marine biodiversity. Biol Conserv 86: 307-315

Veron JE, Done TJ (1979) Corals and coral communities of Lord Howe Island. Aust J Mar Freshw Res 30:203-236

Ward TJ, Jacoby CA (1992) A strategy for assessment and management of marine ecosystems: baseline and monitoring studies in Jervis Bay, a temperate Australian embayment. Mar Pollut Bull 25:163-171

Ward TJ, Vanderklift MA, Nicholls AO, Kenchington RA (1999) Selecting marine reserves using habitats and spatial assemblages as surrogates for biological diversity. Ecol Appl 9:691-698

Warner RR (1995) Large mating aggregations and daily long-distance spawning migrations in the bluehead wrasse, Thalassoma bifasciatum. Environ Biol Fish 44: 337-345

Williams A, Bax NJ (2001) Delineating fish-habitat associations for spatially based management: an example from the south-eastern Australian continental shelf. Mar Freshw Res 52:513-536

Zacharias MA, Roff JC (2000) A hierarchical ecological approach to conserving marine biodiversity. Conserv Biol 14:1327-1334

Zacharias MA, Roff JC (2001a) Use of focal species in marine conservation and management: a review and critique. Aquat Conserv Mar Freshw Ecosyst 11:59-76

Zacharias MA, Roff JC (2001b) Explanations of patterns of intertidal diversity at regional scales. J Biogeogr 28: 471-483

Submitted: September 25, 2006; Accepted: July 11, 2007

Proofs received from author(s): January 4, 2008 